

natureresearch

\title{
Overexpression of the HECT ubiquitin ligase PfUT prolongs the intraerythrocytic cycle and reduces invasion efficiency of Plasmodium falciparum
}

\begin{abstract}
Monika Jankowska-Döllken, Cecilia P. Sanchez, Marek Cyrklaff \& Michael Lanzer (i)*
The glms ribozyme system has been used as an amenable tool to conditionally control expression of genes of interest. It is generally assumed that insertion of the ribozyme sequence does not affect expression of the targeted gene in the absence of the inducer glucosamine-6-phosphate, although experimental support for this assumption is scarce. Here, we report the unexpected finding that integration of the glms ribozyme sequence in the $3^{\prime}$ untranslated region of a gene encoding a HECT E3 ubiquitin ligase, termed Plasmodium falciparum ubiquitin transferase (PfUT), increased steady state RNA and protein levels 2.5 -fold in the human malaria parasite $P$. falciparum. Overexpression of $p$ fut resulted in an S/M phase-associated lengthening of the parasite's intraerythrocytic developmental cycle and a reduced merozoite invasion efficiency. The addition of glucosamine partially restored the wild type phenotype. Our study suggests a role of PfUT in controlling cell cycle progression and merozoite invasion. Our study further raises awareness regarding unexpected effects on gene expression when inserting the glms ribozyme sequence into a gene locus.
\end{abstract}

Many proteins are post-translationally modified by the covalent attachment of a small polypeptide, termed ubiquitin. Ubiquitination serves versatile biological purposes and can earmark a protein for degradation via the proteasome, regulate its enzymatic activity or interaction with other factors, or modulate its intracellular sorting and trafficking route ${ }^{1-5}$. Ubiquitination is catalyzed by a cascade of enzymatic reactions in which ubiquitin is activated, conjugated and finally ligated to the substrate protein ${ }^{6}$.

The human malaria parasite P. falciparum encodes 8 ubiquitin-activating enzymes (E1s), 14 ubiquitin-conjugating enzymes (E2s), and 54 ubiquitin ligases (E3s) ${ }^{7}$. The role of these enzymes in the biology and pathology of $P$. falciparum is only partly understood. For instance, UBA1 (E1), UBC7 (E2) and HRD1 (E3) were identified as major components of the endoplasmic reticulum-associated degradation (ERAD) pathway and were found to be essential ${ }^{8}$. In addition, $P$. falciparum maintains an ERAD-like ubiquitination pathway in the apicoplast, involving PfsUBA1 (E1), PfE2 ${ }_{\mathrm{Ap}}(\mathrm{E} 2)$ and $\mathrm{PfE} 3 \mathrm{c}_{\mathrm{Ap}}(\mathrm{E} 3)$, which are required for protein import into this organelle ${ }^{9,10}$. Furthermore, polymorphisms in two E3 ubiquitin ligases have been associated with reduced susceptibility to the antimalarial drugs pyrimethamine and $\operatorname{artemisinin}^{11,12}$. Other studies have implicated polymorphisms in deubiquitinating enzymes in altered responsiveness to chloroquine and artemisinin derivatives ${ }^{13,14}$.

We have recently associated polymorphisms in a HECT (homologous to E6AP C-terminus) E3 ubiquitin ligase, termed PfUT (MAL7P1.19 or PF3D7_0704600), with altered responsiveness to the antimalarial drug quinine and its enantiomer quinidine ${ }^{15}$. Apart from this report, very little is known about the biological function of this protein. PfUT shares some sequence homologies with the HECT ubiquitin-protein ligase UFD4 of Saccharomyces cerevisiae. UFD4 is a component of the ubiquitin fusion degradation pathway and it is also involved in the proteasome-mediated Arg/ $\mathrm{N}$-end rule pathway by polyubiquitinating proteins earmarked for degradation ${ }^{16}$. PfUT is a large transmembrane protein of $460 \mathrm{kDa}$ localized at the ER/Golgi complex where it seems to associate with other factors forming a mega Dalton complex ${ }^{15}$. PfUT contains several structural features, 
including four predicted transmembrane domains, a catalytically active HECT domain and two long stretches of armadillo (ARM) repeats present in the cytoplasmic C- and N-terminal domains of the protein, respectively. Armadillo repeats typically mediate protein-protein interactions and might play a role in substrate recognition ${ }^{17}$. PfUT is post-translationally modified by phosphorylation at Y347, T372, S411 and $\mathrm{S} 1873^{18}$ and by acetylation at $\mathrm{K}_{2929^{19}}$ (Supplementary Fig. 1). According to the transcription profile ${ }^{20,21}$, pfut is relatively equally expressed throughout the intraerythrocytic cycle, with a slight decrease in late schizonts and merozoites.

Gene disruption studies have provided conflicting results regarding the importance of $p f u t$ in parasite survival. While a study conducted in the mouse malaria model system $P$. berghei, suggested an essential role of the pfut orthologue in parasite biology ${ }^{22}$, another study, this time carried out in P. falciparum, classified the gene as possibly dispensable ${ }^{23}$. To further our understanding of the biological function(s) of PfUT, we attempted to generate a conditional knock-down mutant by inserting the glucosamine-inducible glms ribozyme sequence in the $3^{\prime}$ untranslated region of $p f u t$. The glms riboswitch has previously been used in P. falciparum to conditionally down-regulate the expression of several genes of interest ${ }^{24-29}$. Unexpectedly, insertion of the ribozyme sequence into the $p f u t$ gene locus was not inert, but instead resulted in 2.5 -fold higher steady state transcript levels and associated with it 2.4-fold increased protein amounts, compared with the parental strain. We show that overexpression of $p f u t$ affected the length of the asexual intraerythrocytic life cycle by prolonging the S/M phase. In addition, merozoite invasion efficiency was reduced. Our data suggest that PfUT partakes in the regulatory network that controls merozoite invasion and cell cycle progression during schizogony.

\section{Results}

Generation of a conditional pfut knock-down mutant in P. falciparum. In an effort to elucidate the biological function of PfUT, we generated a conditional knock-down mutant in the P. falciparum line 3D7, by inserting a triple hemagglutinin (HA) tag followed by the glmS ribozyme sequence in the $3^{\prime}$ untranslated region of $p f u t^{27,30}$, via CRISPR-Cas9 genome editing technology ${ }^{31}$ (Fig. 1a). Three independent clones, termed $5 \mathrm{G}, 6 \mathrm{E}$ and $11 \mathrm{~B}$, were isolated by limiting dilution and the desired insertion of the glms ribozyme sequence was confirmed by sequence analysis of the genomic $p f u t$ gene locus ${ }^{32}$ (Fig. 1b,c). This approach followed six unsuccessful attempts each to generate $p f u t$ gene disruption or null mutants, using the selection-linked integration mediated targeted gene disruption (SLI-TGD) method $^{33}$ or the CRISPR-Cas9 method to substitute serine for a functional Cys-3860 in the catalytic domain.

pfut is overexpressed in the mutant lines. We next assessed the potential of the inserted glms ribozyme sequence to down-regulate the expression of pfut. Steady-state RNA levels, indeed, fell by a factor of 3.3 to $30 \%$ of the initial value after either two or 5 days of incubation in the presence of $5 \mathrm{mM}$ glucosamine $(\mathrm{GlcN})(\mathrm{p}<0.001$ according to one way ANOVA Holm-Sidak test), as determined by RT-qPCR (Fig. 2). However, the initial steady state RNA level in the absence of the inducer was 2.5-fold higher than that of the parental 3D7 line, with GlcN treatment having no effect on $p f u t$ mRNA levels in 3D7. Apparently, insertion of the glms ribozyme sequence in the $3^{\prime}$ untranslated region altered pfut RNA stability and/or transcription activity such that it resulted in an overexpression of the genetically altered gene.

Semi-quantitative Western blot analyses, using antibodies specific for PfUT and the internal control $\alpha$-tubulin, confirmed overexpression of the genetically altered $p$ fut gene in the mutant clonal lines (Fig. 3a,b). Compared to the parental strain 3D7, steady state PfUT protein levels were increased 2.4-fold in the mutants. The addition of GlcN decreased PfUT amounts 3.3-fold (by 70\%) to a level slightly below the basal value observed in 3D7. Immunoblotting with antibodies against the HA-tag (expressed as a fusion protein with PfUT in the mutant lines) and $\alpha$-tubulin corroborated the finding of GlcN down-regulating PfUT protein levels in the mutants (Fig. 3a,c). As an additional negative control, we investigated the influence of $p f u t$ overexpression and GlcN treatment on steady state protein levels of the chloroquine resistance transporter PfCRT, but observed no significant effects neither in 3D7 nor in the pfut mutants (Supplementary Fig. 2).

PfUT is localized at the ER/Golgi complex in the mutants. A previous study has localized PfUT at the parasite's ER/Golgi complex ${ }^{15}$. Immunofluorescence assays, using the conditional knock-down mutants, revealed comparable results, with the HA-tagged PfUT partially co-localizing with the ER markers, BiP and ERC, and the Golgi marker, ERD2 (Fig. 4), consistent with previous reports ${ }^{15}$. Immuno-electron microscopy using anti-HA antiserum confirmed a subcellular localization of PfUT at the ER/Golgi complex in the mutant lines (Fig. 5). A comparison of the micrographs with reference electron microscopic images of trophozoites ${ }^{15,34,35}$ provided no evidence of morphological abnormalities in the mutant parasite lines (Fig. 5), suggesting normal phenotypic characteristics of organelles and other subcellular compartments.

pfut mutants displayed a slow proliferation phenotype. We next investigated the effect of pfut overexpression on parasite development. Interestingly, the $p f u t$ mutants grew significantly slower in the absence of GlcN, compared with the parental 3D7 line ( $\mathrm{p}<0.001$ according to F-test statistics) (Fig. 6a and Supplementary Fig. 3). The slow proliferation phenotype was partially reversed in the presence of GlcN (5 mM) (Fig. 6a). Proliferation of the 3D7 was unaffected by GlcN treatment (Fig. 6a and Supplementary Fig. 4).

To better understand the underlying basis of the proliferation defect displayed by the pfut mutants, we determined the parasite multiplication rates and the merozoite numbers generated per schizont ${ }^{36-38}$. The parental $3 \mathrm{D} 7$ line multiplied with a rate of $8 \pm 1$, regardless of the presence of GlcN, consistent with previous reports ${ }^{37}$. In comparison, $p$ fut mutants displayed significantly lower parasite multiplication rates of $5 \pm 1$ ( $\mathrm{p}<0.001$ according to one way ANOVA Holm-Sidak test) and only in the presence of GlcN did their multiplication rates approach values comparable to that of 3D7 (Fig. 6b). In contrast to the multiplication rates, the average number of merozoites generated during schizogony did not differ between $p f u t$ mutants and 3D7 (Fig. 6c). In all cases merozoite 
a

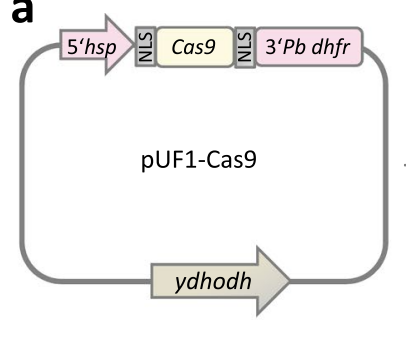

Genomic locus

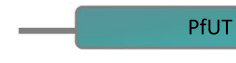

PfUT

Modified locus
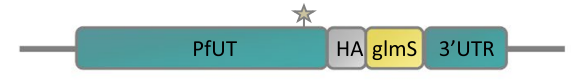

mRNA



mRNA
Degradation



gRNA

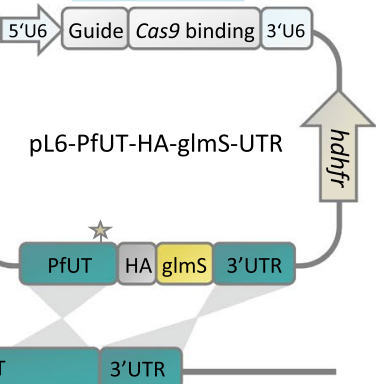

C

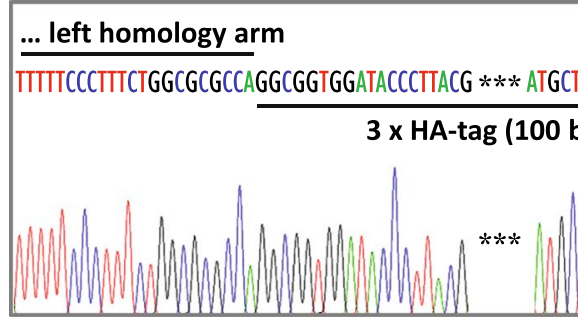

b
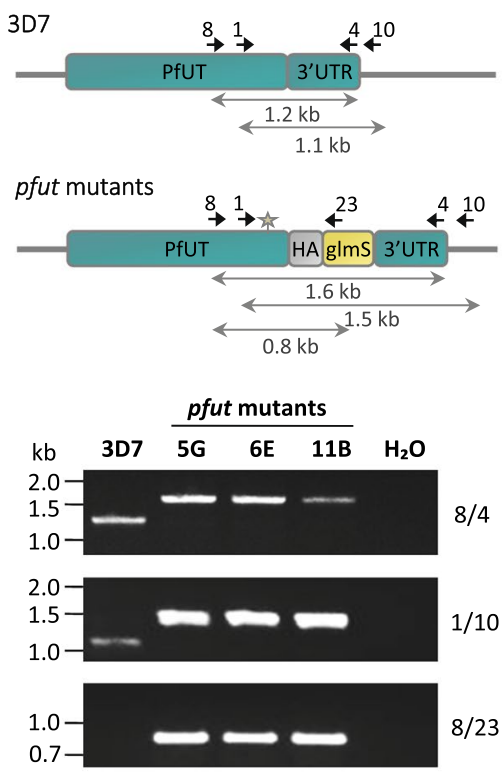

Figure 1. Generation of a conditional pfut knock-down mutant in P. falciparum. (a) Schematic representation of the CRISPR-Cas9-based strategy used to incorporate the HA tag and the glmS ribozyme sequences in the 3 ' untranslated region of the endogenous pfut gene. The cloning strategy and the vectors used are described in the Materials and Methods section. The star indicates a shield mutation that prevents cleavage of the mutated pfut locus by Cas9. Glucosamine ( $\mathrm{GlcN})$ added to the culture medium is taken up by the parasite and converted to the glucosamine-6-phosphate (GlcN6P). Binding of GlcN6P stimulates self-cleavage of the glmS ribozyme, leading to mRNA destabilization and degradation of the transcript and associated with it, down-regulation of the corresponding protein. The GlcN dose-dependent growth curves performed to evaluate the optimal treatment conditions are shown in Supplementary Fig. 4. (b) Analysis of $p f u t$ mutants. The wild type and the genetically altered $p f u t$ locus are shown. The positions of relevant primers for analysis are indicated, as are the sizes of important PCR products. The integration event was verified by PCR, using genomic DNA from the resulting mutants, termed $5 \mathrm{G}, 6 \mathrm{E}, 11 \mathrm{~B}$, and the parental $3 \mathrm{D} 7$ strain. The primer pairs used $(8 / 4,1 / 10$ and $8 / 23)$ are indicated (see Supplementary Table 1 for more details on primers). Primers 8 and 10 are located upstream and downstream of the homology regions, respectively. Size markers are indicated in kilo base pairs (kb). (c) Representative DNA sequence chromatogram of one of the $p f u t$ mutants, showing the correct integration of the triple HA and the glmS ribozyme sequence into the $3^{\prime}$ untranslated region of $p f u t$. This figure was reproduced from the PhD thesis by Jankowska-Döllken ${ }^{32}$.

numbers of $19 \pm 2$ were observed, consistent with previous determinations for $3 \mathrm{D} 7^{38,39}$. However, the merozoite invasion efficiency was low in the pfut mutants and, while it increased in the presence of GlcN, it remained below that of the 3D7 control (Fig. 6d), as determined in synchronized cultures by quantifying the number of ring stages in the next cycle. Since multiple infections could falsify the invasion rate, we quantified the proportion of single, double and triple infections, but found comparable values for both the pfut mutants and the parental line 3D7 (Supplementary Fig. 5).

Slow proliferation is associated with a prolonged S/M-phase in pfut mutants. We next investigated whether the slow proliferation phenotype displayed by pfut mutants can also be attributed to changes in cell cycle duration. To this end, we measured the DNA content of the parasite in highly synchronized cultures in intervals of $4 \mathrm{~h}$ throughout the $48 \mathrm{~h}$ replicative cycle, using flow cytometry. The resulting DNA copy number value or C-value was then analysed as a function of time post invasion. In 3D7, the C-value increased from 1 to 2 around $26 \pm 2 \mathrm{~h}$ post invasion (Fig. 7a) as DNA replication commenced with the beginning of the S/M-like 


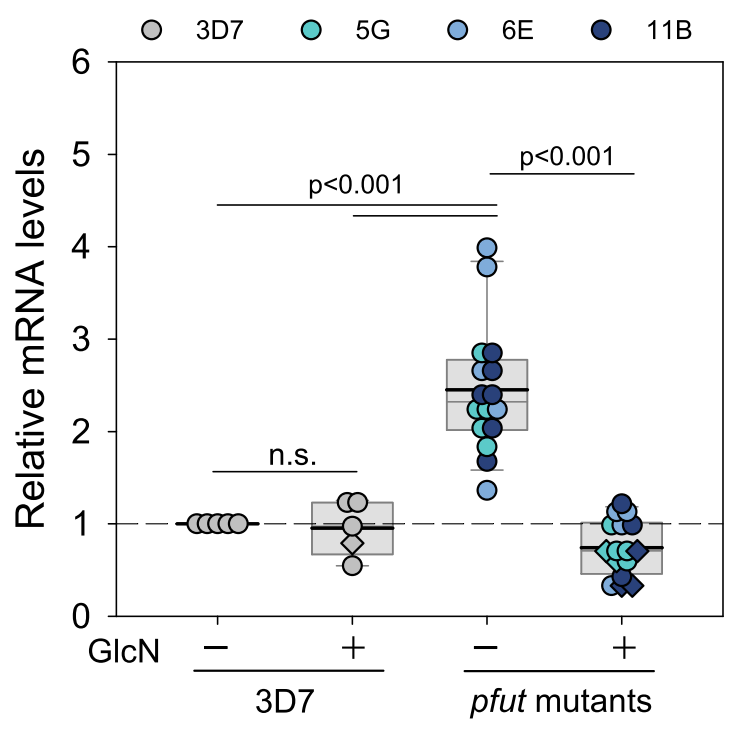

Figure 2. RT-qPCR analysis of steady state $p f u t$ transcript levels in the $p f u t$ mutant lines and the parental 3D7 strain. Total mRNA was isolated from the $p f u t$ mutants and 3D7 cultured in the presence or absence of $5 \mathrm{mM}$ GlcN. The amount of steady state $p f u t$ transcripts were then quantified by RT-qPCR and normalized to the housekeeping gene $\beta$-tubulin followed by normalization to the $p$ fut steady state RNA level in untreated 3D7. Trophozoites were analyzed throughout. Validation of the qPCR primers is depicted in Supplementary Fig. 6. Data derived from cells treated for $48 \mathrm{~h}$ (one cell cycle) and $120 \mathrm{~h}$ (three cell cycles) are indicated by rhombuses and circles, respectively. Each symbol represents an independent biological replicate. A box plot analysis is overlaid over the individual data points, with the median (thin grey line), mean (thick black line) and the $25 \%$ and $75 \%$ quartile ranges being shown. Statistical significance between the data sets was calculated using Holm-Sidak one way ANOVA. n.s. - not significant. This figure was reproduced from the PhD thesis by Jankowska-Döllken ${ }^{32}$.

phase, consistent with previous reports ${ }^{40,41}$. The C-value then peaked at $46 \pm 2 \mathrm{~h}$ post invasion before it rapidly dropped $^{21,42}$ (Fig. 7a), which marks the end of the replicative cycle and the rupture of the infected erythrocyte and the release of daughter merozoites. In the case of the $p$ fut mutants, the replicative cycle was extended by approximately $8 \mathrm{~h}$ and instead of $48 \mathrm{~h}$ lasted $56 \mathrm{~h}$ (Fig. 7a,d). The extended intraerythrocytic life cycle was associated with a prolonged S/M-phase and a slower overall DNA replication rate, whereby the S/M-phase commenced at the same time point post invasion and C-values reached comparable peaks, in both 3D7 and pfut mutants (Fig. 7a and Table 1). In parallel experiments, we investigated the cell cycle characteristics in cells treated with GlcN for one or three replicative cycles (Fig. 7 and Supplementary Fig. 3). No differences were observed after treatment for one cycle, with the S/M phase still being prolonged by approximately $8 \mathrm{~h}$ in the mutants, compared with 3D7 (Fig. 7b and Table 1). In comparison, exposure to GlcN for three cycles partially restored the length of the S/M phase and the cell cycle to $24 \mathrm{~h}$ and $52 \mathrm{~h}$, respectively, in pfut mutants (Fig. $7 \mathrm{c}, \mathrm{d}$ and Table 1). The cell cycle length remained unaffected by GlcN treatment in 3D7.

\section{Discussion}

There have been conflicting results of whether or not $p f u t$ is essential for intraerythrocytic development of $P$. falciparum. Whereas studies conducted in $P$. berghei have suggested a critical function for the PfUT homologue in the biology of the mouse malaria parasite ${ }^{22}$, studies performed in P. falciparum have concluded that PfUT is likely dispensable during intraerythroyctic development, on the basis of the accessibility of the corresponding gene locus to piggyBac transposon mutagenesis ${ }^{23}$ (Supplementary Fig. 1), although it is not clear whether the latter strategy resulted in null mutants or partially active mutants that still maintained some PfUT activity. To assess the importance of PfUT during blood stage development, we applied the SLI-TGD method to the pfut locus in 6 independent experiments, but did not obtain the desired disruption mutation, which according to criteria defined by Birnbaum et al. ${ }^{33}$ suggests that $p f u t$ is an essential gene during intraerythrocytic development. Further suggesting an essential role of $p f u t$ during blood stage development, the active, thioester intermediate forming amino acid cysteine at position 3860 within the catalytic HECT domain could not be replaced with serine, in spite of three attempts and the fact that the same CRISPR-Cas9 guide RNA was used as for the successful integration of the glms ribozyme sequence in the $3^{\prime}$ end of the $p$ fut locus.

The intention to integrate the glms ribozyme in the $3^{\prime}$ end of the $p f u t$ locus was to generate a conditional knock-down mutant for further functional analyses ${ }^{32}$ (Fig. 1). While we got the mutant and although treatment of the cells with glucosamine down-regulated $p f u t$ expression levels by a factor of 3.3, a knock-down was not obtained in stricto sensu as integration of the glms ribozyme sequence led to approximately 2.5 -fold increased steady state RNA and protein levels, compared with the parental 3D7 strain (Figs. 2 and 3a,b). It seems that the genetic manipulation stabilized the mRNA and protected it from degradation or, alternatively, stimulated transcriptional activity. Other studies have also noted an effect of the glms ribozyme on expression levels, at least in qualitative terms ${ }^{28,29}$. 
a
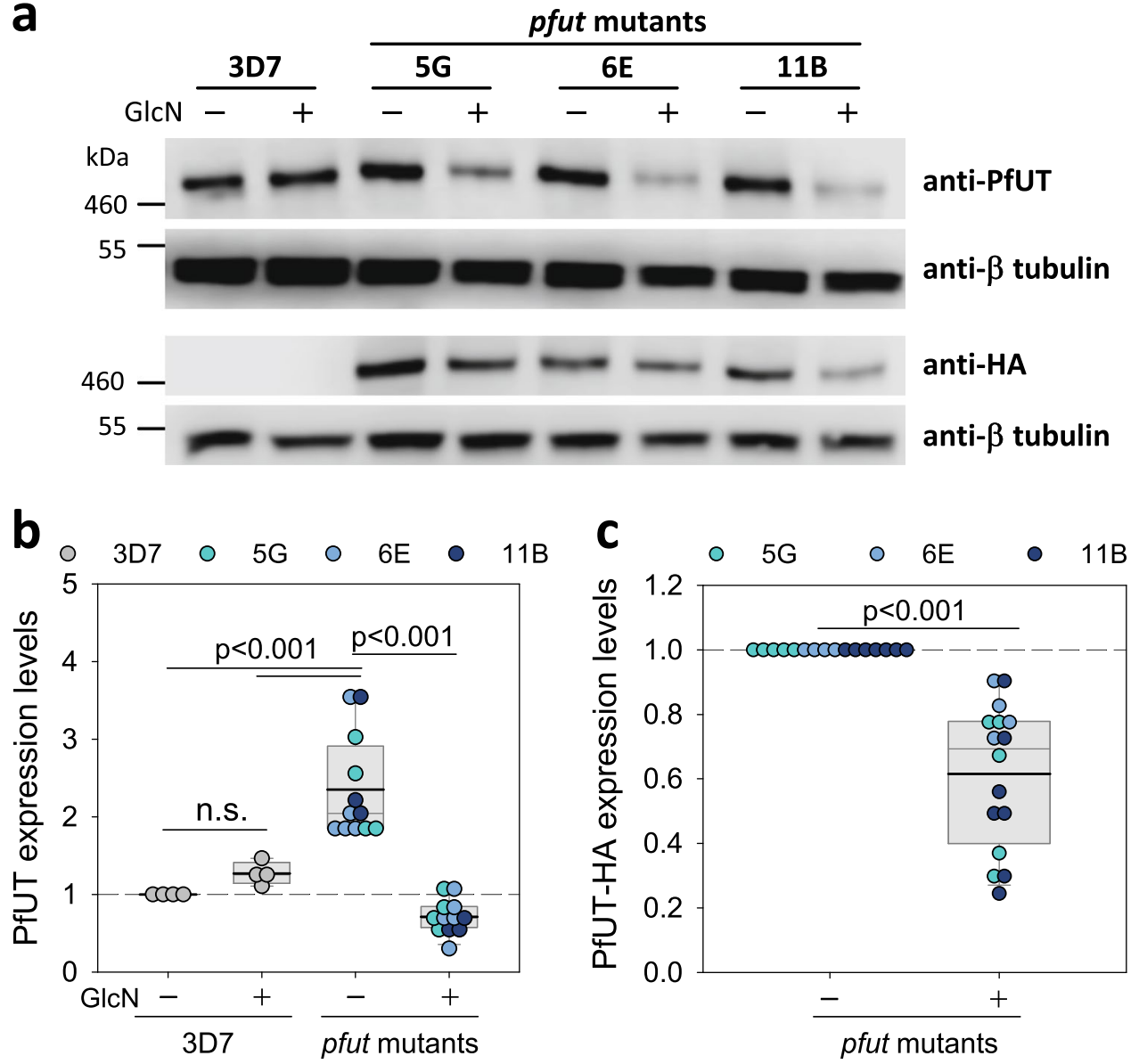

Figure 3. Steady state PfUT protein levels in the $p f u t$ mutants and the parental 3D7 strain. (a) Western blot analysis. Total protein lysates were prepared from late trophozoites cultured for $120 \mathrm{~h}$ in the presence or absence of $5 \mathrm{mM}$ GlcN. Proteins were fractionated by SDS-PAGE and transferred to a PVDF membrane. The following antisera were used: anti-PfUT (raised against residues 473 to 712 of the N-terminal domain; rabbit; 1:1000); anti- $\alpha$-tubulin (mouse, 1:1000); and anti-HA-tag (mouse, 1:1000). Representative Western blots are shown. Blots were cropped at the top and bottom to show the bands of interest. The uncropped, full-length blots are presented in Supplementary Fig. 9a (first and second panel) and 9b (third and fourth panel). A size marker is indicated in $\mathrm{kDa}$. (b) The amount of steady state PfUT was quantified, on the basis of the anti-PfUT hybridization signal intensities, and normalized to the $\alpha$-tubulin followed by normalization to steady state PfUT protein levels in untreated 3D7. Each symbol represents an independent biological replicate. A box plot analysis is overlaid over the individual data points, with the median (thin grey line), mean (thick black line) and the $25 \%$ and $75 \%$ quartile ranges being shown. Statistical significance between the data sets was calculated using Holm-Sidak one way ANOVA. n.s. - not significant. (c) As in (b) with the exception that the anti-HA signal intensities were analyzed and normalized to the corresponding $\alpha$-tubulin signal followed by normalization to steady state PfUT-HA protein levels in untreated $p f u t$ mutants. This figure was reproduced from the $\mathrm{PhD}$ thesis by Jankowska-Döllken ${ }^{32}$.

Altering the gene locus did not affect trafficking or sub-cellular localization of PfUT, with PfUT being localized at the ER/Golgi complex (Figs. 4 and 5), consistent with previous reports ${ }^{15}$.

Which essential role $p f u t$ plays during parasite development is still unclear. Previous studies have ascribed PfUT a function in the ubiquitin fusion degradation pathway, on the basis of homologies to the characterized HECT E3 ubiquitin-protein ligase UFD4 of S. cerevisiae ${ }^{16}$ and because PfUT interacts with components of the proteasome in a yeast-two-hybrid screen ${ }^{43}$. Another study has implicated PfUT, respectively polymorphisms within PfUT, in reduced responsiveness to quinine and its enantiomer quinidine ${ }^{15}$. Our finding that the expression level of pfut can modulate the cell cycle length by prolonging the S/M-like phase was unexpected (Fig. 7). However, this finding is consistent with the reported role of E3 ubiquitin ligases, including those of the HECT subclass, in signalling pathways that regulate cell cycle progression, as shown in other system ${ }^{44-47}$. In particular the G1/S transition is tightly controlled by the ubiquitin proteasome system ${ }^{48}$. However, the onset of DNA replication was not altered in the pfut mutants (Fig. 7 and Table 1), suggesting a functional, non-PfUT dependent checkpoint between the G1 and S/M phase. Thus, PfUT seems to participate in the network that coordinates schizogony, the unconventional cell division by which P. falciparum and other malaria parasites reproduce and which is characterized by multiple rounds of DNA replication and nuclear division without cytokinesis. 

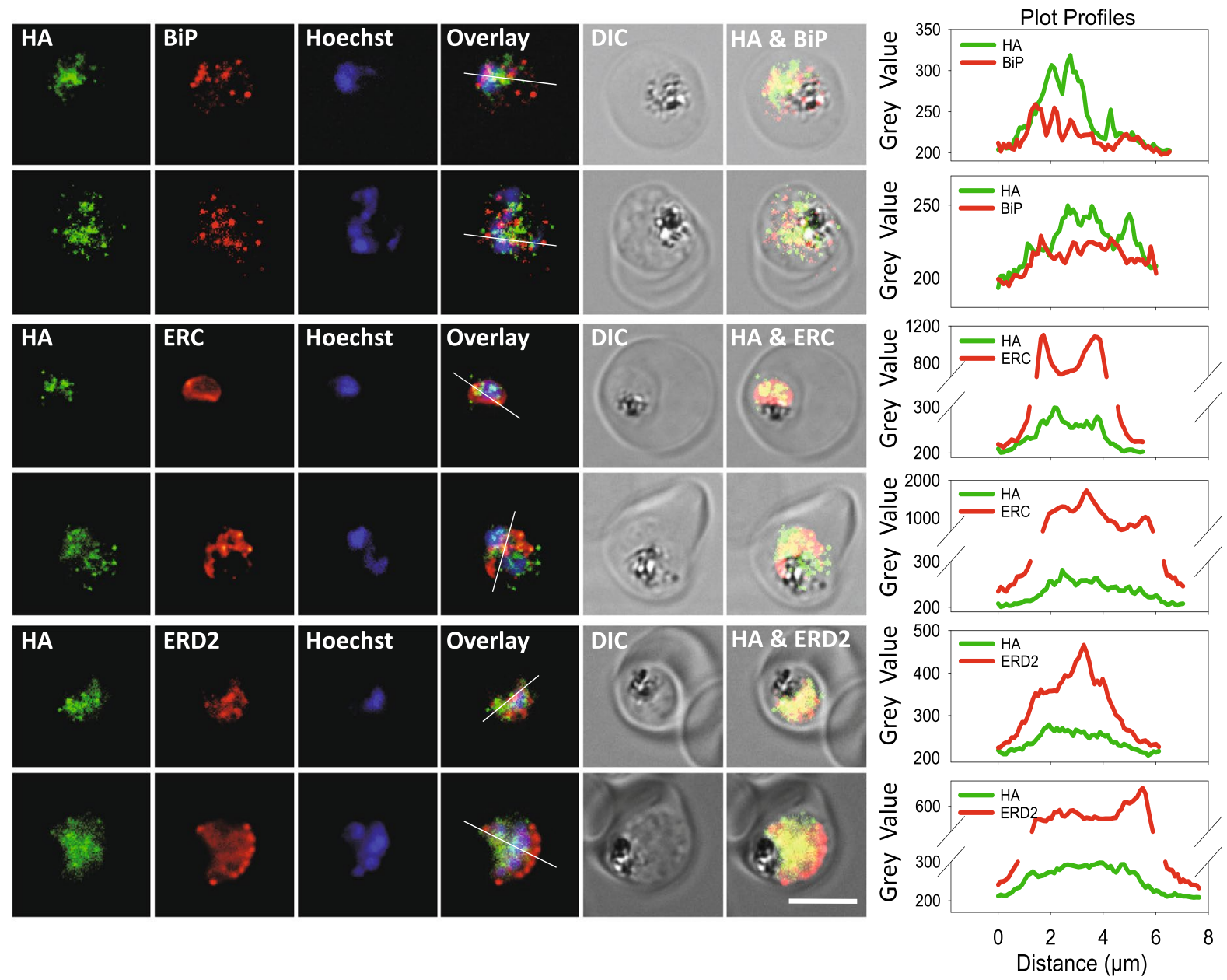

Figure 4. Colocalization of PfUT-HA with ER and Golgi markers in $p f u t$ mutants. Indirect immunofluorescence assay (IFA), using $p f u t$ mutants (at the trophozoite stage) and an anti-HA antiserum (mouse, 1:1000) together with the ER marker BiP (rabbit, 1:1000) or ERC (rabbit, 1:500), or with the Golgi marker ERD2 (rabbit, 1:500). Secondary antibodies were an anti-mouse Alexa Fluor 488 (green) and an antirabbit Alexa Fluor 546 (red). The nuclei were visualized with Hoechst (blue). Different channels, the differential interference contrast (DIC) image and two overlay images are shown for two representative examples each. The plot profiles are included for a better presentation of signal colocalization. Colocalization of anti-HA and antiPfUT fluorescence signals is shown in Supplementary Fig. 7. Scale bar: $5 \mu \mathrm{m}$. This figure was reproduced from the $\mathrm{PhD}$ thesis by Jankowska-Döllken ${ }^{32}$.

Previous studies have identified several factors that control cell cycle progress in $P$. falciparum. This includes cyclins (encoded by $p f c y c 1-4$ genes), cyclin-dependent protein kinases (CDKs), CDK-related kinases $(\mathrm{CRKs})^{40,41,49-53}$, calcium-dependent protein kinases (CDPKs) ${ }^{54,55}$ or the cyclic GMP-dependent protein kinase $\mathrm{PfPKG}^{41,56}$. Which, if any, of these factors are targeted by PfUT for degradation remains to be seen. In this context it is noteworthy that in silico studies have predicted an interaction between PfUT and a plasmodial homologue of cell division cycle 48 (CDC48) ${ }^{7}$. As shown in other systems, CDC48, an AAA-type ATPase, is involved in the ERAD pathway by pumping misfolded and polyubiquitinated proteins from the ER into the cytoplasm where these proteins are degraded by the proteasome ${ }^{7,8,57,58}$. Notably, in yeasts, CDC48 has been associated with the degradation of cell cycle regulators ${ }^{59}$.

We further noted an effect of $p f u t$ on merozoite invasion efficiency (Fig. 6d). Interestingly, a yeast two-hybrid screen has previously identified the merozoite surface protein 1 (MSP1) and the rhoptry neck protein RON2 as interaction partners of PfUT ${ }^{43}$. Both proteins are critically involved in merozoite egress and/or invasion ${ }^{60-64}$. For instance, MSP1 destabilizes the membrane skeleton of the host erythrocytes, which, in turn, promotes red blood cell rupture and merozoite release ${ }^{60}$. Other studies have shown that MSP1 recruits variable peripheral proteins and that the ensuing supermolecular complex interacts with ligands on the red blood cell, in particular glycophorin A and band 3, to initiate the invasion process by the merozoite ${ }^{61,62,65}$. RON2 forms a complex with the apical membrane antigen 1 (AMA1), which plays a pivotal role during invasion by triggering junction formation ${ }^{63}$. In summary, our data suggest a role of PfUT in merozoite invasion and cell cycle coordination. Overexpression of PfUT distorts these processes, possibly, by PfUT targeting, accidentally or in an untimely fashion, factors critical for invasion and cell cycle regulation for degradation, thereby prolonging the S/M phase and reducing merozoite invasion efficiency. 


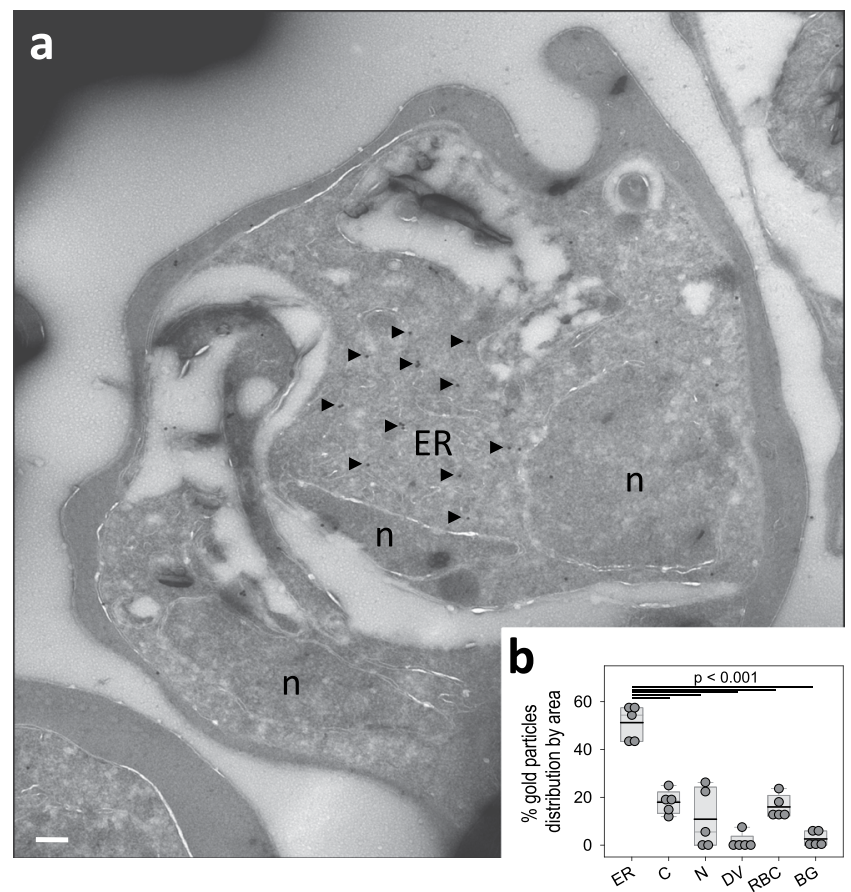

Figure 5. Subcellular localization of PfUT by immunoelectron microscopy. (a) A representative micrograph is shown of an erythrocyte infected with a $p f u t$ mutant. The sample was prepared according to the Tokuyasu protocol, and immunolabelled with anti-HA antiserum (mouse, 1:1), followed by staining with an anti-mouse antibody coupled to $10 \mathrm{~nm}$ colloidal gold (goat, 1:20). Arrowheads point towards gold label. n, nucleus; ER, endoplasmic reticulum/Golgi complex. Scale bar, $200 \mathrm{~nm}$. (b) Quantification of immuno EM results. The distribution of gold grains was determined in 5 micrographs and analyzed according to their subcellular localization. Gold grains were significantly more present in areas of the ER/Golgi complex (ER) than in other subcellular compartments, including the parasite's cytoplasm (C), nucleus (N), digestive vacuole (DV), red blood cell cytosol (RBC) and non-cellular background (BG). Each symbol represents data derived from an individual parasitized erythrocyte. A box plot analysis is overlaid over the individual data points, with the median (thin grey line), mean (thick black line) and the $25 \%$ and $75 \%$ quartile ranges being shown. Statistical significance between the data sets was assessed using the Holm-Sidak one way ANOVA test. This figure was reproduced from the $\mathrm{PhD}$ thesis by Jankowska-Döllken ${ }^{32}$.

\section{Methods}

In vitro culture of $P$. falciparum. Parasites were cultured in human A+ erythrocytes and complete RPMI medium (10\% human A serum, $0.2 \mu \mathrm{g} \mathrm{ml}^{-1}$ gentamycin, $0.1 \mathrm{mM}$ hypoxanthine) at 2-4\% haematocrit, according to standard protocols ${ }^{66}$. Human red blood cells and human sera were purchased from the Deutsche Rote Kreuz-Blutspendedienst Baden-Württemberg/Hessen GmbH. Parasite cultures were synchronized using 5\% D-sorbitol ${ }^{67}$. For tight synchronization, a combination of sorbitol and heparin $\left(50 \mathrm{U} \mathrm{ml}^{-1}\right)$ was used ${ }^{68,69}$.

Oligonucleotides. Primers used for PCR amplification, sequencing and qPCR are depicted in Supplementary Table 1.

Generation of the glms ribozyme transfection construct. The appropriate homology regions were amplified from genomic DNA of 3D7, using primers $1 / 2$ and 3/4 and cloned into the pL6-HA-glmS plasmid, using restriction endonucleases SpeI/BssHII and NarI/AflII, respectively. The guide RNA (primers 5/6) was cloned into the BtgZI linearized final pL6-PfUT-HA-glmS-UTR vector, using the In Fusion cloning technology (Clontech Laboratories).

Transfection of $\boldsymbol{P}$. falciparum. P. falciparum ring stage parasites at 3-5\% parasitemia were electroporated with $100 \mu \mathrm{g}$ of the appropriate transfection vectors (pL6 and pUF1-Cas9), as previously described ${ }^{70}$. Transfectants were selected using $5 \mathrm{nM}$ WR99210 and $1.5 \mu \mathrm{M}$ DSM1 ${ }^{31}$ and maintained in RPMI medium supplemented with $5 \%$ human A serum, $0.25 \%$ Albumax I, $0.2 \mu \mathrm{g} \mathrm{ml}^{-1}$ gentamycin and $0.2 \mathrm{mM}$ hypoxanthine. Clonal parasite populations were obtained by limiting dilution. The genetically engineered $p f u t$ locus was confirmed for each clone by sequencing analysis, using primers $8-10$ and 22-25, after amplification using total genomic DNA and primers 8 and 10.

RT-qPCR. Total RNA was extracted from trophozoite-stage $P$. falciparum cultures, using the Trizol-chloroform method. The cells were centrifuged at $4^{\circ} \mathrm{C}$ for $2 \mathrm{~min}$ at $900 \times \mathrm{g}$, with brake-off at $130 \times \mathrm{g}$. The pellet was lysed in ice cold $0.2 \%$ saponin, washed in ice cold PBS and finally resuspended in the Trizol reagent. For phase separation, 
a

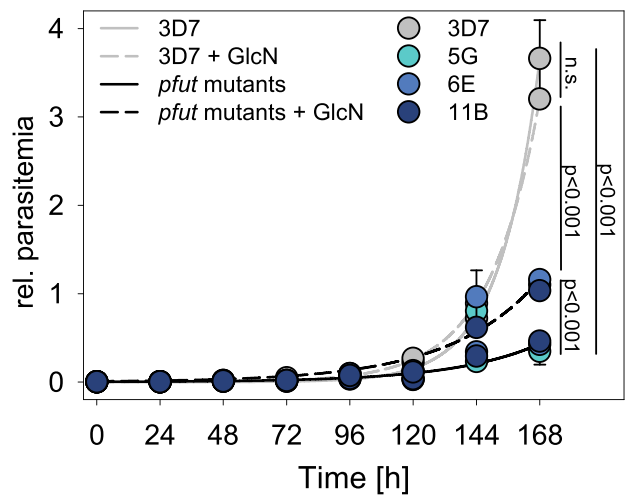

C

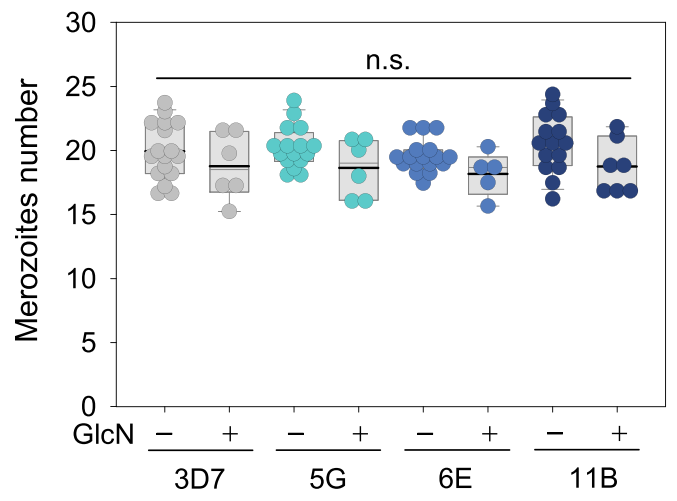

b

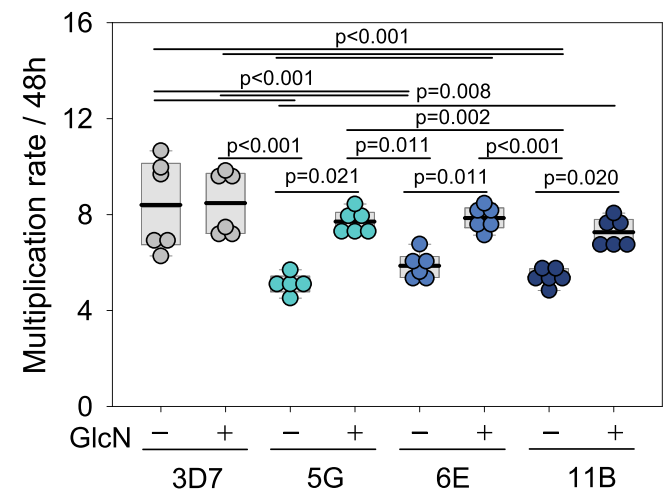

d

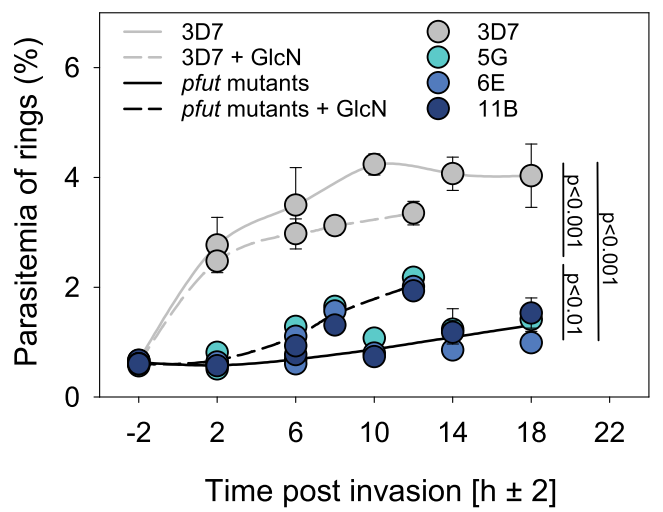

Figure 6. Phenotypic characterization of $P$. falciparum pfut mutants. (a) Asexual intraerythrocytic proliferation. Proliferation of the three independent $p$ fut mutants $(5 \mathrm{G}, 6 \mathrm{E}$ and $11 \mathrm{~B})$ and the parental line 3D7 was determined over $168 \mathrm{~h}$ in the presence and absence of $5 \mathrm{mM} \mathrm{GlcN}$. Time point 0 indicates the time point at which the cell culture was split and one aliquot was incubated in the presence of GlcN. The other aliquot served as the untreated control. The relative parasitemia represents the sum of the parasitemia in the culture, taking into account the splitting/dilution factors. Each symbol represents the mean $\pm S D$ of three independent biological replicates. A single two parameter exponential growth function was fitted to the data points. Statistical significance was assessed using the F-test. (b) Multiplication rate. The parasite multiplication rate (PMR) was determined for each clone as the fold increase in parasitemia per $48 \mathrm{~h}$, measured over 4 cycles. (c) Merozoites number. The number of merozoites generated per schizont was determined in the presence and absence of $5 \mathrm{mM}$ GlcN, using flow cytometry. Each symbol represents an independent biological replicate. A box plot analysis is overlaid over the individual data points, with the median (thin grey line), mean (thick black line) and the $25 \%$ and $75 \%$ quartile ranges being shown. Statistical significance was assessed using Holm-Sidak one way ANOVA. n.s. - not significant. (d) Merozoite invasion efficiency. Synchronized parasites at the late schizont stage were allowed to re-invade and the number of ring stage parasites was quantified over time. The mean \pm SD of three independent biological replicates is shown. Statistical significance was assessed using the F-test. This figure was reproduced from the PhD thesis by Jankowska-Döllken ${ }^{32}$.

$200 \mu \mathrm{l}$ of chloroform were added per $1 \mathrm{ml}$ of Trizol. The mixture was vigorously shaken by hand, incubated for $3 \mathrm{~min}$ at RT and centrifuged at $10500 \times \mathrm{g}$ for $30 \mathrm{~min}$ at $4^{\circ} \mathrm{C}$. The upper aqueous phase containing RNA was collected and precipitated by adding $500 \mu \mathrm{l}$ of isopropanol per $1 \mathrm{ml}$ of Trizol. The mixture was incubated at $-80^{\circ} \mathrm{C}$ for at least $30 \mathrm{~min}$ and subsequently centrifuged at $10500 \times \mathrm{g}$ for $10 \mathrm{~min}$ at $4^{\circ} \mathrm{C}$. The pellet was washed with cold $70 \%$ ethanol and centrifuged at $10500 \times \mathrm{g}$ for $10 \mathrm{~min}$ at $4^{\circ} \mathrm{C}$. The RNA pellet was then air-dried at RT to eliminate any trace of ethanol, and dissolved in $30 \mu \mathrm{l}$ of ribonuclease-free water. The possible genomic DNA contamination was removed from the freshly isolated RNA samples using the DNase Treatment and Removal Kit (Invitrogen), according to the manufacturer's instructions. Subsequently, the cDNA was synthesized using the SuperScript III First-Strand Synthesis SuperMix (Invitrogen), following the protocol provided by the manufacturer. The cDNA

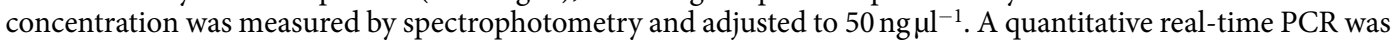
performed using the ABI 7500 Real-Time PCR detection system and the FastStart Universal SYBR Green Master ROX (Roche). Samples were analyzed in 96-well plates, in technical triplicates (each containing $200 \mathrm{ng}$ of cDNA), using the following primer pairs: for $p f u t$, primers $26 / 27$; for $\beta$-tubulin, primers $28 / 29$. A control without template DNA was analysed in parallel as a negative control. The qPCR thermocycling conditions included polymerase activation at $95^{\circ} \mathrm{C}$ for $10 \mathrm{~min}$, followed by 40 cycles of denaturation $\left(95^{\circ} \mathrm{C}\right.$ for $\left.15 \mathrm{sec}\right)$, annealing $\left(55^{\circ} \mathrm{C}\right.$ for $\left.15 \mathrm{sec}\right)$ 

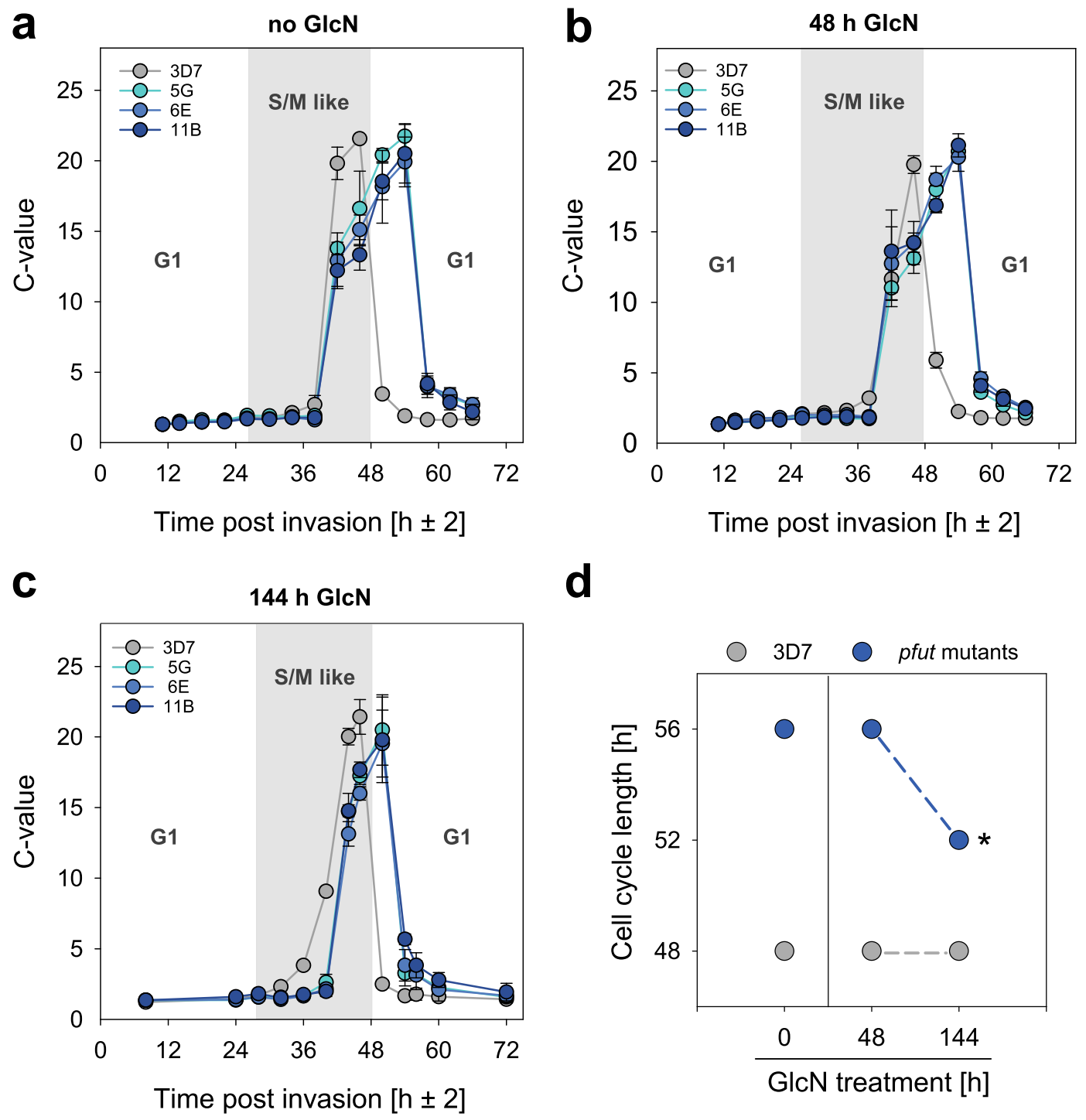

Figure 7. Analysis of the cell cycle length in pfut mutants and 3D7. The DNA copy number (C-value) was determined in highly synchronized cells in intervals of $4 \mathrm{~h}$ throughout the $48 \mathrm{~h}$ replicative cycle. (a) Cell cycle in the absence of GlcN; (b) after one cycle in the presence of $5 \mathrm{mM} \mathrm{GlcN}$; (c) after three cycles in the presence of $5 \mathrm{mM}$ GlcN. The drop in the C-value after reaching the peak indicates the beginning of a new cycle. Each data point represents the mean $\pm \mathrm{SD}$ of three independent biological replicates. The G1 and S/M-like phase of the $48 \mathrm{~h}$ intraerythrocytic cell cycle of 3D7 are indicated to better display the differences with $p f u t$ mutants. (d) Cell cycle length as a function of GlcN treatment for $48 \mathrm{~h}$ (one replicative cycle) and $144 \mathrm{~h}$ (three replicative cycles) in pfut mutants and 3D7. " $\mathrm{p}<0.001$, compared with the untreated pfut mutant cell lines, according to Student's t-test. This figure was reproduced from the PhD thesis by Jankowska-Döllken ${ }^{32}$.

and elongation $\left(60^{\circ} \mathrm{C}\right.$ for $\left.45 \mathrm{sec}\right)$. Data were analyzed using the delta-delta $\mathrm{Ct}$ method taking into account primers efficiencies (Supplementary Fig. 6).

Western blot. P. falciparum trophozoite stage parasites were purified using the magnetic activated cell sorting (MACS) system (Miltenyi Biotec). Parasitized erythrocytes were lysed with $0.7 \%$ saponin in the presence of protease inhibitors (Roche) for $3 \mathrm{~min}$ on ice, centrifuged for $1 \mathrm{~min}$ at $17000 \times \mathrm{g}$ at $4^{\circ} \mathrm{C}$ and washed 3 times in ice cold PBS containing protease inhibitors. Parasites were then lysed in 4 pellet volumes of RIPA buffer $(50 \mathrm{mM}$ Tris pH 7.5, $150 \mathrm{mM} \mathrm{NaCl}, 5 \mathrm{mM}$ EDTA, $50 \mathrm{mM} \mathrm{NaF}, 0.5 \%$ NaDOC, $0.1 \%$ SDS, $1 \%$ Triton X-100, $2 \mathrm{mM}$ DTT, $1 \mathrm{mM}$ PMSF, protease inhibitors) containing $10 \mu \mathrm{g} \mathrm{ml}^{-1}$ DNase I for $30 \mathrm{~min}$ on ice and centrifuged for $20 \mathrm{~min}$ at $17000 \times \mathrm{g}$ at $4{ }^{\circ} \mathrm{C}$. Protein lysates (supernatant) were transferred to a fresh Eppendorf tube, resuspended in 1:1 ratio with 2x Protein Loading Buffer (3\% SDS, $250 \mathrm{mM}$ Tris pH 6.8, 20\% Glycerol, 0.1\% Bromophenol blue) containing $\beta$-mercaptoethanol and stored at $-20^{\circ} \mathrm{C}$. Samples and the HiMark Pre-Stained HMW Protein Standard (31 to $460 \mathrm{kDa}$; Invitrogen) were loaded on NuPAGE Tris-Acetate 3-8\% gradient gels (Invitrogen). Gels were run at $150 \mathrm{~V}$ and $40 \mathrm{~mA}$ for approx. $1.5 \mathrm{~h}$. Protein transfer from the gel onto a PVDF membrane was carried out for $1 \mathrm{~h}$ at $230 \mathrm{~mA}$ and $30 \mathrm{~V}$ using XCell II Blot Module (Thermo Fisher Scientific). The membrane was 


\begin{tabular}{|c|c|c|c|c|}
\hline Treatment & Clone & $\begin{array}{l}\text { Onset of DNA replication } \\
\text { [h p.i.] }\end{array}$ & $\begin{array}{l}\text { Peak of the C-value } \\
\text { [h p.i.] }\end{array}$ & $\begin{array}{l}\text { Length of the S/M-like } \\
\text { phase }[\mathrm{h}]\end{array}$ \\
\hline \multirow{4}{*}{$\begin{array}{l}1 \text { st cycle } \\
(- \text { GlcN })\end{array}$} & $3 \mathrm{D} 7$ & $26 \pm 2$ & $46 \pm 2$ & $20 \pm 2$ \\
\hline & $5 \mathrm{G}$ & $26 \pm 2$ & $54 \pm 2^{*}$ & $28 \pm 2 *$ \\
\hline & $6 \mathrm{E}$ & $26 \pm 2$ & $54 \pm 2 *$ & $28 \pm 2 *$ \\
\hline & $11 \mathrm{~B}$ & $26 \pm 2$ & $54 \pm 2^{*}$ & $28 \pm 2 *$ \\
\hline \multirow{4}{*}{$\begin{array}{l}1 \text { st cycle } \\
(+ \text { GlcN })\end{array}$} & 3D7 & $26 \pm 2$ & $46 \pm 2$ & $20 \pm 2$ \\
\hline & $5 \mathrm{G}$ & $26 \pm 2$ & $54 \pm 2^{*}$ & $28 \pm 2 *$ \\
\hline & $6 \mathrm{E}$ & $26 \pm 2$ & $54 \pm 2^{*}$ & $28 \pm 2 *$ \\
\hline & $11 \mathrm{~B}$ & $26 \pm 2$ & $54 \pm 2^{*}$ & $28 \pm 2 *$ \\
\hline \multirow{4}{*}{$\begin{array}{l}\text { 3rd cycle } \\
(+ \text { GlcN })\end{array}$} & 3D7 & $28 \pm 2$ & $46 \pm 2$ & $18 \pm 2$ \\
\hline & $5 \mathrm{G}$ & $28 \pm 2$ & $50 \pm 2^{*, \#}$ & $22 \pm 2^{*, \#}$ \\
\hline & \begin{tabular}{|l|}
$6 \mathrm{E}$ \\
\end{tabular} & $28 \pm 2$ & $50 \pm 2^{*, \#}$ & $22 \pm 2^{*, \#}$ \\
\hline & $11 \mathrm{~B}$ & $28 \pm 2$ & $50 \pm 2^{*, \#}$ & $22 \pm 2^{*, \#}$ \\
\hline
\end{tabular}

Table 1. Cell cycle characteristics for $p$ fut mutants and 3D7. The following parameters are indicated: the onset of DNA replication, as defined by the time point post invasion (p.i.) when the C-value reaches 2; the time point of maximal C-value; and the length of the S/M phase. Data are shown for cells cultured in the absence of GlcN and cells treated for one and three replicative cycles with $5 \mathrm{mM} \mathrm{GlcN}$. ${ }^{\mathrm{p}}<0.001$, compared with the parental line 3D7, according to Holm-Sidak one way ANOVA. ${ }^{*} \mathrm{p}<0.001$, compared with untreated $p f u t$ mutant cultures, according to Holm-Sidak one way ANOVA.

blocked in 5\% milk and incubated with the respective primary and subsequently secondary antibodies diluted in $1 \%$ BSA. The following antibodies were used: mouse anti- $\alpha$-tubulin (1:1000; Sigma Aldrich), mouse anti-HA clone 12CA5 (1:1000; Roche), rabbit anti-PfUT clone 1-2a raised against residues 473 to 712 of the N-terminal domain $(1: 1000)^{15}$, guinea pig anti-PfCRT (1:1000; custom-made by Eurogentec) $)^{71}$, rabbit anti-Ub FL-76 (1:2000; Santa Cruz Biotechnology), goat anti-mouse-POD (1:10000; Jackson ImmunoResearch), goat anti-rabbit-POD (1:10000; Jackson ImmunoResearch) and donkey anti-guinea pig-POD (1:5000; Jackson ImmunoResearch). The mouse anti-HA and the rabbit anti-PfUT antibodies colocalized at PfUT (Supplementary Fig. 7). Signals were detected using the LiCor C-DiGit Blot Scanner and images were processed using Image Studio software.

Immunofluorecence assay (IFA). Parasites at the trophozoite stage were either purified using the MACS system or collected unpurified from erythrocytes at a parasitemia of 5-10\%. Samples were centrifuged at $900 \times \mathrm{g}$ for $2 \mathrm{~min}$. Erythrocytes were washed in PBS, followed by fixation in $4 \%$ paraformaldehyde and $0.0075 \%$ glutaraldehyde for $30 \mathrm{~min}$ at RT, with rotation. Samples were then washed twice with PBS and kept at $4{ }^{\circ} \mathrm{C}$ or directly incubated with $0.1 \%$ Triton X-100 and $125 \mathrm{mM}$ glycine for $15 \mathrm{~min}$ at RT, with rotation. All the following treatments were conducted at RT, with rotation. 3\% BSA in PBS was used as blocking buffer and as antibodies dilution buffer. Samples were blocked for at least $2 \mathrm{~h}$, followed by primary antibody staining for $1.5 \mathrm{~h}$ (or at $4{ }^{\circ} \mathrm{C}$ overnight). Cells were then washed in 3\% BSA in PBS 3 times for $15 \mathrm{~min}$, followed by secondary antibody staining for $45 \mathrm{~min}$ in the dark. Samples were then washed with PBS 3 times for $15 \mathrm{~min}$, including addition of $5 \mu \mathrm{M}$ Hoechst to the final wash. Cells were resuspended in PBS and stored at $4{ }^{\circ} \mathrm{C}$ until imaging. Samples were imaged using the Carl Zeiss Axiovert 25 widefield miscroscope using objective with $63 \mathrm{x}$ magnification. Images were acquired and processed in FIJI. The following antibodies were used: mouse anti-HA clone 12CA5 (1:1000; Roche), rabbit anti-PfUT N-terminal clone 1-2a $(1: 1000)^{15}$, rabbit anti-BiP $(1: 1000)^{72}$, rabbit anti-PfERC $(1: 500)^{73}$, rabbit anti-PfERD2 (1:500) ${ }^{74}$, goat Alexa Fluor 488 anti-mouse IgGs (1:1000; Invitrogen) and goat Alexa Fluor 546 anti-rabbit IgGs (1:500; Invitrogen).

Transmission electron microscopy (TEM). Immunogold-labelled samples for transmission electron microscopy (TEM) were prepared according to the Tokuyasu method ${ }^{75}$. To this end, erythrocytes infected with trophozoites were purified from uninfected red blood cells using MACS system. After elution from the column, parasitized erythrocytes were centrifuged for $2 \mathrm{~min}$ at $900 \times \mathrm{g}$ and the pellet was washed twice with $1 \mathrm{x}$ PHEM (60 mM PIPES, $25 \mathrm{mM}$ HEPES, $10 \mathrm{mM}$ EGTA and $2 \mathrm{mM} \mathrm{MgCl}_{2}, \mathrm{pH}$ 6.9) buffer. The sample was fixed in $4 \%$ paraformaldehyde and $0.016 \%$ glutaraldehyde in 1x PHEM buffer for $1 \mathrm{~h}$ at RT under agitation and subsequently washed twice in 1x PHEM. Pellet was resuspended in 1:1 ratio in 1x PHEM followed by embedding in 10-12\% gelatine. Samples were incubated for $5 \mathrm{~min}$ at $37^{\circ} \mathrm{C}$, shortly pelleted and solidified on ice. Gelatinized samples were cut into small cubes (around $1 \mathrm{~mm}^{3}$ ) and infused with a $2.3 \mathrm{M}$ sucrose solution for cryo-protection (at $4^{\circ} \mathrm{C}$ with light agitation overnight). The cubes were mounted on metal pins with excess of sucrose solution and frozen in liquid nitrogen. Subsequently, the frozen cubes were sectioned, using the cryo-ultramicrotome (Leica, UCT6), melted on a drop of sucrose/methyl cellulose solution $(2.3 \mathrm{M} / 1.5 \%)$ and mounted onto TEM grids coated with Formvar film. Immuno-labelling was preceded by incubation in quenching buffer (50 mM glycine in PBS) for $30 \mathrm{~min}$ to quench the remains of free aldehyde fixatives, followed by soaking in blocking buffer containing $1.5 \%$ BSA and $0.1 \%$ fish skin gelatine in $1 \mathrm{x}$ PBS for $30 \mathrm{~min}$. This blocking buffer was also used as a dilution buffer for antibodies. Tokuyasu cryo-sections were labelled with primary mouse anti-HA antibody (dilution $1: 1$ ) for $1 \mathrm{~h}$ at RT and washed 5 times $3 \mathrm{~min}$ in the quenching buffer. Subsequent labelling with secondary goat anti-mouse antibody coupled to $10 \mathrm{~nm}$ colloidal gold (dilution 1:20) was carried out for $1 \mathrm{~h}$ at RT followed by washing 3 times 
in quenching buffer and 3 times in $\mathrm{ddH}_{2} \mathrm{O}$, for 3 min each. Cryo-sections were then fixed in $1 \%$ glutaraldehyde for $5 \mathrm{~min}$ at RT, followed by washing 5 times for $3 \mathrm{~min}$ in $\mathrm{ddH}_{2} \mathrm{O}$. To enhance the contrast and to embed the samples, the sections were washed in a mixture of uranyl acetate and methyl cellulose $(1.8 \% / 0.8 \%)$ and air dried. Specimens were examined and images recorded using Jeol JEM-1400 transmission electron microscope. ER/ Golgi complex was determined as membranous compartments adjacent to nuclei, including the margin of $50 \mathrm{~nm}$ at each side of a membrane for the accuracy of labelling that takes into consideration the cumulative length of the primary and secondary antibodies and the size of the protein A gold marker. The distribution of gold particles was analyzed stereologically according to their subcellular localization in the infected red blood cell on several micrographs. For this purpose, a square grid with known spacing was placed over each of the micrographs to facilitate the quantification of gold hits and the number of line intersections which define the area of a compartment. For each compartment, gold counts were determined and depicted as percentage of the total number of gold particles in the analyzed area, as well as was the compartment area presented as percentage of the total analyzed area. Subsequently, the ratios of gold counts per compartment area were generated for each subcellular region to obtain the number of gold hits per unit area. These values were then depicted as a proportion of total gold signal measured across all analyzed compartments of several micrographs.

Flow cytometry based analyses. Parasite DNA was stained using SYBR Green, as described by Ganter et al. ${ }^{41}$. Parasites were fixed in $4 \%$ paraformaldehyde and $0.0075 \%$ glutaraldehyde at $4{ }^{\circ} \mathrm{C}$ overnight. Samples were then washed several times with PBS and stored in PBS at $4^{\circ} \mathrm{C}$. $200 \mu \mathrm{l}$ of each sample were transferred to a 96 -well V-bottom plate, centrifuged for $2 \mathrm{~min}$ at $900 \times \mathrm{g}$ and permeabilized with $200 \mu \mathrm{l}$ of $0.1 \%$ Triton X-100 for 8 min at RT. Cells were washed twice with PBS, and subsequently treated with $200 \mu \mathrm{l} \mathrm{of} 0.3 \mathrm{mg} \mathrm{m}^{-1}$ RNase A for $30 \mathrm{~min}$ at $37^{\circ} \mathrm{C}$. Samples were then washed twice with PBS and kept at $4^{\circ} \mathrm{C}$ until staining. Cells were incubated with $200 \mu \mathrm{l}$ of SYBR Green I (1:2000 in PBS) for $20 \mathrm{~min}$ at RT in the dark. Stained samples were then washed twice with PBS, transferred to FACS tubes containing $1 \mathrm{ml}$ of cold PBS and run on a BD FACSCanto flow cytometer. SYBR Green fluorescence was detected in the fluorescein isothiocyanate (FITC) channel. For each sample 50,000 events were recorded and analyzed using Flowing Software. The FSC-H versus FSC-A plot was first used to discriminate doublets from single cells. Singlets gate was further used for analysis of FITC positive events. The unstained sample served as a negative control used for gating of uninfected erythrocytes.

The parasitemia was quantified as a ratio of FITC positive cells representing infected erythrocytes to the total number of red blood cells analyzed per one flow cytometry measurement. In addition, we distinguished between single, double, and triple P. falciparum infections ${ }^{76}$. For the analysis of multiple infections, highly synchronized ring stage parasite cultures were used. The populations of single-, double- and triple-infected erythrocytes were determined via a defined gating on dot plot and histogram (Supplementary Fig. 8).

In order to quantify the parasite multiplication rates (PMR), parasite cultures were synchronized using sorbitol and heparin treatments and diluted to $0.1 \%$ parasitemia at the trophozoite stage. $200 \mu \mathrm{l}$ of each of three independent biological replicates were collected every $48 \mathrm{~h}$ over 4 cycles, fixed, stained with SYBR Green and run on a BD FACSCanto flow cytometer. Data were analyzed using Flowing Software, Excel and Sigma Plot 13. Data points were plotted in a scatter plot depicting parasitemia expressed as the natural logarithm over the time of 4 replicative cycles. A linear regression was then fitted to the data points and the parasite multiplication rate (PMR) was quantified as $P M R=e^{a}$, where $a$ corresponds to the slope of the linear regression.

The number of merozoites generated per schizont was determined via flow cytometric analysis of the DNA content in mature schizonts. Parasites were synchronized using sorbitol and heparin treatments. Samples were collected, fixed, stained with SYBR Green and run on a BD FACSCanto flow cytometer. Data were analyzed using Flowing Software and Sigma Plot 13. The merozoites number was expressed as a mean fluorescence emitted by a population of schizonts (containing multiple DNA copy numbers), divided by a mean intensity obtained for a population of single-infected red blood cells (with DNA copy number of one). The populations of schizonts and single-infected erythrocytes were determined via a defined gating strategies (Supplementary Fig. 8).

Cell cycle progression of $P$. falciparum can be tracked using flow cytometry, by quantification of the increase in DNA content over time. In order to determine the intraerythroycytic cycle duration, parasite cultures were synchronized within a $4 \mathrm{~h}$ window, using sorbitol and heparin, and adjusted to $0.5 \%$ ring stage parasitemia. The cell cycle length was analyzed as previously described ${ }^{41}$, by measuring the parasite DNA content (C-value) at $4 \mathrm{~h}$ intervals over at least $60 \mathrm{~h}$. At each time point, $200 \mu \mathrm{l}$ of each of three independent biological replicates were collected, fixed, stained and run on a BD FACSCanto. Data were analyzed using Flowing Software, Excel and Sigma Plot 13. The $\mathrm{C}$-value was quantified by dividing the total parasite mean fluorescence intensity at particular time point by the mean intensity of a single infection from the first time point. The visible drop of the C-value after reaching the peak at schizont stage indicates the beginning of a new cycle.

Statistical analysis. Data are given as mean \pm standard deviation (SD) throughout this study, if not indicated otherwise. The independent biological replicates are indicated as individual data points on the figures. Statistical analyses were performed, using the Sigma Plot (v.13, Systat) software. Statistical significance was assessed using the Holm-Sidak one way analysis of variance test, Student's t-test or F-test, where indicated.

\section{Data availability}

The authors declare that the data supporting the findings of this study are available within the article and supplementary information files, or are available from the authors upon request.

Received: 11 July 2019; Accepted: 18 November 2019;

Published online: 04 December 2019 


\section{References}

1. Woelk, T., Sigismund, S., Penengo, L. \& Polo, S. The ubiquitination code: a signalling problem. Cell Div 2, 11, https://doi. org/10.1186/1747-1028-2-11 (2007).

2. Wang, G. et al. K63-linked ubiquitination in kinase activation and cancer. Front Oncol 2, 5, https://doi.org/10.3389/fonc.2012.00005 (2012).

3. Suryadinata, R., Roesley, S. N. A., Yang, G. \& Sarčević, B. Mechanisms of generating polyubiquitin chains of different topology. Cells 3, 674-689, https://doi.org/10.3390/cells3030674 (2014).

4. Sadowski, M. \& Sarcevic, B. Mechanisms of mono- and poly-ubiquitination: Ubiquitination specificity depends on compatibility between the E2 catalytic core and amino acid residues proximal to the lysine. Cell Div 5, 19, https://doi.org/10.1186/1747-1028-5-19 (2010).

5. Perrett, C. A., Lin, D. Y. \& Zhou, D. Interactions of bacterial proteins with host eukaryotic ubiquitin pathways. Front Microbiol 2, 143, https://doi.org/10.3389/fmicb.2011.00143 (2011).

6. Doug Chung, D.-W., Ponts, N., Cervantes, S. \& Le Roch, K. G. Post-translational modifications in Plasmodium: More than you think! Mol Biochem Parasitol 168, 123-134, https://doi.org/10.1016/j.molbiopara.2009.08.001 (2009).

7. Ponts, N. et al. Deciphering the ubiquitin-mediated pathway in apicomplexan parasites: a potential strategy to interfere with parasite virulence. PLoS One 3, e2386, https://doi.org/10.1371/journal.pone.0002386 (2008).

8. Chung, D.-W. D., Ponts, N., Prudhomme, J., Rodrigues, E. M. \& Le Roch, K. G. Characterization of the ubiquitylating components of the human malaria parasite's protein degradation pathway. PLoS one 7, e43477, https://doi.org/10.1371/journal.pone.0043477 (2012).

9. Spork, S. et al. An unusual ERAD-like complex is targeted to the apicoplast of Plasmodium falciparum. Eukaryot Cell 8, 1134-1145, https://doi.org/10.1128/EC.00083-09 (2009).

10. Agrawal, S. et al. An apicoplast localized ubiquitylation system is required for the import of nuclear-encoded plastid proteins. PLoS Pathog 9, e1003426, https://doi.org/10.1371/journal.ppat.1003426 (2013).

11. Takala-Harrison, S. et al. Genetic loci associated with delayed clearance of Plasmodium falciparum following artemisinin treatment in Southeast Asia. Proc Natl Acad Sci USA 110, 240-245, https://doi.org/10.1073/pnas.1211205110 (2013).

12. Park, D. J. et al. Sequence-based association and selection scans identify drug resistance loci in the Plasmodium falciparum malaria parasite. Proc Natl Acad Sci USA 109, 13052-13057, https://doi.org/10.1073/pnas.1210585109 (2012).

13. Hunt, P. et al. Gene encoding a deubiquitinating enzyme is mutated in artesunate- and chloroquine-resistant rodent malaria parasites. Mol Microbiol 65, 27-40, https://doi.org/10.1111/j.1365-2958.2007.05753.x (2007).

14. Henriques, G. et al. Directional selection at the $p f m d r 1$, pfcrt, pfubp1, and pfap2mu loci of Plasmodium falciparum in Kenyan children treated with ACT. J Infect Dis 210, 2001-2008, https://doi.org/10.1093/infdis/jiu358 (2014).

15. Sanchez, C. P. et al. A HECT ubiquitin-protein ligase as a novel candidate gene for altered quinine and quinidine responses in Plasmodium falciparum. PLoS Genet 10, e1004382, https://doi.org/10.1371/journal.pgen.1004382 (2014).

16. Hwang, C.-S., Shemorry, A., Auerbach, D. \& Varshavsky, A. The N-end rule pathway is mediated by a complex of the RING-type Ubr1 and HECT-type Ufd4 ubiquitin ligases. Nat Cell Biol 12, 1177-1185, https://doi.org/10.1038/ncb2121 (2010).

17. Tewari, R., Bailes, E., Bunting, K. A. \& Coates, J. C. Armadillo-repeat protein functions: questions for little creatures. Trends Cell Biol 20, 470-481, https://doi.org/10.1016/j.tcb.2010.05.003 (2010).

18. Pease, B. N. et al. Global analysis of protein expression and phosphorylation of three stages of Plasmodium falciparum intraerythrocytic development. J Proteome Res 12, 4028-4045, https://doi.org/10.1021/pr400394g (2013).

19. Cobbold, S. A., Santos, J. M., Ochoa, A., Perlman, D. H. \& Llinás, M. Proteome-wide analysis reveals widespread lysine acetylation of major protein complexes in the malaria parasite. Sci Rep 6, 19722, https://doi.org/10.1038/srep19722 (2016).

20. Llinás, M., Bozdech, Z., Wong, E. D., Adai, A. T. \& DeRisi, J. L. Comparative whole genome transcriptome analysis of three Plasmodium falciparum strains. Nucleic Acids Res 34, 1166-1173, https://doi.org/10.1093/nar/gkj517 (2006).

21. Bozdech, Z. et al. The transcriptome of the intraerythrocytic developmental cycle of Plasmodium falciparum. PLoS Biol 1, e5, https:// doi.org/10.1371/journal.pbio.0000005 (2003).

22. Bushell, E. et al. Functional profiling of a Plasmodium genome reveals an abundance of essential genes. Cell 170, 260-272 e268, https://doi.org/10.1016/j.cell.2017.06.030 (2017).

23. Zhang, M. et al. Uncovering the essential genes of the human malaria parasite Plasmodium falciparum by saturation mutagenesis. Science 360, eaap7847, https://doi.org/10.1126/science.aap7847 (2018).

24. Cobb, D. W. et al. The exported chaperone PfHsp70x is dispensable for the Plasmodium falciparum intraerythrocytic life cycle. mSphere 2, https://doi.org/10.1128/mSphere.00363-17 (2017).

25. Ghosh, S. et al. The cysteine protease dipeptidyl aminopeptidase 3 does not contribute to egress of Plasmodium falciparum from host red blood cells. PLoS One 13, e0193538, https://doi.org/10.1371/journal.pone.0193538 (2018).

26. Aroonsri, A. et al. Identifying antimalarial compounds targeting dihydrofolate reductase-thymidylate synthase (DHFR-TS) by chemogenomic profiling. Int J Parasitol 46, 527-535, https://doi.org/10.1016/j.ijpara.2016.04.002 (2016).

27. Prommana, P. et al. Inducible knockdown of Plasmodium gene expression using the glmS ribozyme. PLoS One 8, e73783, https://doi. org/10.1371/journal.pone.0073783 (2013).

28. Marapana, D. S. et al. Plasmepsin V cleaves malaria effector proteins in a distinct endoplasmic reticulum translocation interactome for export to the erythrocyte. Nat Microbiol 3, 1010-1022, https://doi.org/10.1038/s41564-018-0219-2 (2018).

29. Ito, D., Schureck, M. A. \& Desai, S. A. An essential dual-function complex mediates erythrocyte invasion and channel-mediated nutrient uptake in malaria parasites. Elife 6, https://doi.org/10.7554/eLife.23485 (2017).

30. Elsworth, B. et al. PTEX is an essential nexus for protein export in malaria parasites. Nature 511, 587-591, https://doi.org/10.1038/ nature13555 (2014).

31. Ghorbal, M. et al. Genome editing in the human malaria parasite Plasmodium falciparum using the CRISPR-Cas9 system. Nat Biotechnol 32, 819, https://doi.org/10.1038/nbt.2925 (2014).

32. Jankowska-Döllken, M. Functional studies on the chloroquine resistance transporter (PfCRT) and the HECT E3 ubiquitin-protein ligase (PfUT) in Plasmodium falciparum. PhD thesis, Heidelberg University (2019).

33. Birnbaum, J. et al. A genetic system to study Plasmodium falciparum protein function. Nat Methods 14, 450-456, https://doi. org/10.1038/nmeth.4223 (2017).

34. Sherling, E. S. et al. The Plasmodium falciparum rhoptry protein RhopH3 plays essential roles in host cell invasion and nutrient uptake. eLife 6, e23239, https://doi.org/10.7554/eLife.23239 (2017).

35. Muregi, F. W., Ohta, I., Masato, U., Kino, H. \& Ishih, A. Resistance of a rodent malaria parasite to a thymidylate synthase inhibitor induces an apoptotic parasite death and imposes a huge cost of fitness. PLoS one 6, e21251, https://doi.org/10.1371/journal. pone.0021251 (2011).

36. Reilly, H. B., Wang, H., Steuter, J. A., Marx, A. M. \& Ferdig, M. T. Quantitative dissection of clone-specific growth rates in cultured malaria parasites. Int J Parasitol 37, 1599-1607, https://doi.org/10.1016/j.ijpara.2007.05.003 (2007).

37. Murray, L. et al. Multiplication rate variation in the human malaria parasite Plasmodium falciparum. Sci Rep 7, 6436, https://doi. org/10.1038/s41598-017-06295-9 (2017).

38. Garg, S. et al. Visualization and quantification of Plasmodium falciparum intraerythrocytic merozoites. Syst Synth Biol 9, 23-26, https://doi.org/10.1007/s11693-015-9167-9 (2015). 
39. Rovira-Graells, N., Aguilera-Simon, S., Tinto-Font, E. \& Cortes, A. New assays to characterise growth-related phenotypes of Plasmodium falciparum reveal variation in density-dependent growth inhibition between parasite lines. PLoS One 11, e0165358, https://doi.org/10.1371/journal.pone.0165358 (2016).

40. Matthews, H., Duffy, C. W. \& Merrick, C. J. Checks and balances? DNA replication and the cell cycle in Plasmodium. Parasit Vectors 11, 216-216, https://doi.org/10.1186/s13071-018-2800-1 (2018).

41. Ganter, M. et al. Plasmodium falciparum CRK4 directs continuous rounds of DNA replication during schizogony. Nat Microbiol 2, 17017, https://doi.org/10.1038/nmicrobiol.2017.17 (2017).

42. van Biljon, R. et al. Inducing controlled cell cycle arrest and re-entry during asexual proliferation of Plasmodium falciparum malaria parasites. Sci Rep 8, 16581, https://doi.org/10.1038/s41598-018-34964-w (2018).

43. LaCount, D. J. et al. A protein interaction network of the malaria parasite Plasmodium falciparum. Nature 438, 103-107, https://doi. org/10.1038/nature04104 (2005).

44. Wickliffe, K., Williamson, A., Jin, L. \& Rape, M. The multiple layers of ubiquitin-dependent cell cycle control. Chem Rev 109, 1537-1548, https://doi.org/10.1021/cr800414e (2009).

45. Munoz, M. A. et al. The E3 ubiquitin ligase EDD regulates S-phase and G2/M DNA damage checkpoints. Cell Cycle 6, 3070-3077, https://doi.org/10.4161/cc.6.24.5021 (2007).

46. Lu, L. et al. The HECT type ubiquitin ligase NEDL2 is degraded by anaphase-promoting complex/cyclosome (APC/C)-Cdh1, and its tight regulation maintains the metaphase to anaphase transition. J Biol Chem 288, 35637-35650, https://doi.org/10.1074/jbc. M113.472076 (2013).

47. Hall, J. R. et al. Cdc6 stability is regulated by the Huwe1 ubiquitin ligase after DNA damage. Mol Biol Cell 18, 3340-3350, https://doi. org/10.1091/mbc.e07-02-0173 (2007).

48. Rizzardi, L. F. \& Cook, J. G. Flipping the switch from G1 to S phase with E3 ubiquitin ligases. Genes Cancer 3, 634-648, https://doi. org/10.1177/1947601912473307 (2012).

49. Robbins, J. A., Absalon, S., Streva, V. A. \& Dvorin, J. D. The malaria parasite cyclin $\mathrm{H}$ homolog PfCyc1 is required for efficient cytokinesis in blood-stage Plasmodium falciparum. mBio 8, e00605-00617, https://doi.org/10.1128/mBio.00605-17 (2017).

50. Le Roch, K. G. et al. Discovery of gene function by expression profiling of the malaria parasite life cycle. Science 301, 1503-1508, https://doi.org/10.1126/science.1087025 (2003).

51. Iwanaga, T. et al. Characterization of Plasmodium falciparum cdc2-related kinase and the effects of a CDK inhibitor on the parasites in erythrocytic schizogony. Parasitol Int 62, 423-430, https://doi.org/10.1016/j.parint.2013.05.003 (2013).

52. Halbert, J. et al. A Plasmodium falciparum transcriptional cyclin-dependent kinase-related kinase with a crucial role in parasite proliferation associates with histone deacetylase activity. Eukaryot Cell 9, 952-959, https://doi.org/10.1128/EC.00005-10 (2010).

53. Graeser, R., Wernli, B., Franklin, R. M. \& Kappes, B. Plasmodium falciparum protein kinase 5 and the malarial nuclear division cycles. Mol Biochem Parasitol 82, 37-49, https://doi.org/10.1016/0166-6851(96)02716-8 (1996).

54. Kumar, P. et al. Regulation of Plasmodium falciparum development by calcium-dependent protein kinase 7 (PfCDPK7). J Biol Chem 289, 20386-20395, https://doi.org/10.1074/jbc.M114.561670 (2014).

55. Absalon, S. et al. Calcium-dependent protein kinase 5 is required for release of egress-specific organelles in Plasmodium falciparum. MBio 9, e00130-00118, https://doi.org/10.1128/mBio.00130-18 (2018).

56. Alam, M. M. et al. Phosphoproteomics reveals malaria parasite protein kinase $\mathrm{G}$ as a signalling hub regulating egress and invasion. Nat Commun 6, 7285, https://doi.org/10.1038/ncomms8285 (2015).

57. Wang, L. et al. Characterization of the 26 S proteasome network in Plasmodium falciparum. Sci Rep 5, 17818, https://doi.org/10.1038/ srep17818 (2015).

58. Imamura, S., Yabu, T. \& Yamashita, M. Protective role of cell division cycle 48 (CDC48) protein against neurodegeneration via ubiquitin-proteasome system dysfunction during zebrafish development. J Biol Chem 287, 23047-23056, https://doi.org/10.1074/ jbc.M111.332882 (2012).

59. Ye, Y. Diverse functions with a common regulator: Ubiquitin takes command of an AAA ATPase. J Struct Biol 156, 29-40, https:// doi.org/10.1016/j.jsb.2006.01.005 (2006)

60. Das, S. et al. Processing of Plasmodium falciparum merozoite surface protein MSP1 activates a spectrin-binding function enabling parasite egress from RBCs. Cell Host Microbe 18, 433-444, https://doi.org/10.1016/j.chom.2015.09.007 (2015).

61. Lin, C. S. et al. Multiple Plasmodium falciparum merozoite surface protein 1 complexes mediate merozoite binding to human erythrocytes. J Biol Chem 291, 7703-7715, https://doi.org/10.1074/jbc.M115.698282 (2016).

62. Baldwin, M. R., Li, X., Hanada, T., Liu, S. C. \& Chishti, A. H. Merozoite surface protein 1 recognition of host glycophorin A mediates malaria parasite invasion of red blood cells. Blood 125, 2704-2711, https://doi.org/10.1182/blood-2014-11-611707 (2015).

63. Srinivasan, P. et al. Binding of Plasmodium merozoite proteins RON2 and AMA1 triggers commitment to invasion. Proc Natl Acad Sci USA 108, 13275-13280, https://doi.org/10.1073/pnas.1110303108 (2011).

64. Srinivasan, P. et al. Disrupting malaria parasite AMA1-RON2 interaction with a small molecule prevents erythrocyte invasion. Nat Commun 4, 2261, https://doi.org/10.1038/ncomms3261 (2013).

65. Goel, V. K. et al. Band 3 is a host receptor binding merozoite surface protein 1 during the Plasmodium falciparum invasion of erythrocytes. Proc Natl Acad Sci USA 100, 5164-5169, https://doi.org/10.1073/pnas.0834959100 (2003).

66. Trager, W. \& Jensen, J. B. Human malaria parasites in continuous culture. Science 193, 673-675, https://doi.org/10.1126/ science.781840 (1976).

67. Lambros, C. \& Vanderberg, J. P. Synchronization of Plasmodium falciparum erythrocytic stages in culture. J Parasitol 65, 418-420 (1979).

68. Kobayashi, K. \& Kato, K. Evaluating the use of heparin for synchronization of in vitro culture of Plasmodium falciparum. Parasitol Int 65, 549-551, https://doi.org/10.1016/j.parint.2016.09.002 (2016).

69. Boyle, M. J., Richards, J. S., Gilson, P. R., Chai, W. \& Beeson, J. G. Interactions with heparin-like molecules during erythrocyte invasion by Plasmodium falciparum merozoites. Blood 115, 4559-4568, https://doi.org/10.1182/blood-2009-09-243725 (2010).

70. Wu, Y., Sifri, C. D., Lei, H. H., Su, X. Z. \& Wellems, T. E. Transfection of Plasmodium falciparum within human red blood cells. Proc Natl Acad Sci USA 92, 973-977, https://doi.org/10.1073/pnas.92.4.973 (1995).

71. Sanchez, C. P. et al. Phosphomimetic substitution at Ser-33 of the chloroquine resistance transporter PfCRT reconstitutes drug responses in Plasmodium falciparum. J Biol Chem 294, 12766-12778, https://doi.org/10.1074/jbc.RA119.009464 (2019).

72. Pesce, E. R. et al. The Plasmodium falciparum heat shock protein 40, Pfi4, associates with heat shock protein 70 and shows similar heat induction and localisation patterns. Int J Biochem Cell Biol 40, 2914-2926, https://doi.org/10.1016/j.biocel.2008.06.011 (2008).

73. Adisa, A., Albano, F. R., Reeder, J., Foley, M. \& Tilley, L. Evidence for a role for a Plasmodium falciparum homologue of Sec. 31p in the export of proteins to the surface of malaria parasite-infected erythrocytes. J Cell Sci 114, 3377-3386 (2001).

74. Elmendorf, H. G. \& Haldar, K. Plasmodium falciparum exports the Golgi marker sphingomyelin synthase into a tubovesicular network in the cytoplasm of mature erythrocytes. J Cell Biol 124, 449-462, https://doi.org/10.1083/jcb.124.4.449 (1994).

75. Cyrklaff, M. et al. Hemoglobins S and C interfere with actin remodeling in Plasmodium falciparum-infected erythrocytes. Science 334, 1283-1286, https://doi.org/10.1126/science.1213775 (2011).

76. Bei, A. K. et al. A flow cytometry-based assay for measuring invasion of red blood cells by Plasmodium falciparum. Am J Hematol 85, 234-237, https://doi.org/10.1002/ajh.21642 (2010) 


\section{Acknowledgements}

M.J.D. acknowledges Dr. Ryan Henrici, Dr. Markus Ganter and Jessika Kehrer for technical support regarding Western blotting, flow cytometry and IFA, respectively, Dr. José Juan Lopez Rubio and Artur Scherf for the CRISPR-Cas9 and the pL6-HA-glms vector, Dr. Tobias Spielmann for the pSLI-TGD plasmid and Dr. Jude Przyborski for providing the ER/Golgi markers used in IFA. M.L. is a member of the research cluster of excellence CellNetworks. M.J.D. was a PhD student at the HBIGS graduate school at Heidelberg University. The data underpinning this study are part of the $\mathrm{PhD}$ thesis by M.J.D. ${ }^{32}$.

\section{Author contributions}

C.P.S. and M.L. designed the study. M.J.D. and M.C. performed the experiments. M.J.D., M.C. and M.L. analyzed the data. M.J.D. and M.L. wrote the manuscript. All authors participated in discussion and manuscript editing.

\section{Competing interests}

The authors declare no competing interests.

\section{Additional information}

Supplementary information is available for this paper at https://doi.org/10.1038/s41598-019-54854-z.

Correspondence and requests for materials should be addressed to M.L.

Reprints and permissions information is available at www.nature.com/reprints.

Publisher's note Springer Nature remains neutral with regard to jurisdictional claims in published maps and institutional affiliations.

(c) (i) Open Access This article is licensed under a Creative Commons Attribution 4.0 International License, which permits use, sharing, adaptation, distribution and reproduction in any medium or format, as long as you give appropriate credit to the original author(s) and the source, provide a link to the Creative Commons license, and indicate if changes were made. The images or other third party material in this article are included in the article's Creative Commons license, unless indicated otherwise in a credit line to the material. If material is not included in the article's Creative Commons license and your intended use is not permitted by statutory regulation or exceeds the permitted use, you will need to obtain permission directly from the copyright holder. To view a copy of this license, visit http://creativecommons.org/licenses/by/4.0/.

(C) The Author(s) 2019 